$$
\text { CONF-9605222-1 }
$$

BNL- 62938

\title{
THE USE OF CHEMICAL MARKERS IN THE EVALUATION \\ OF CRUDE OIL BIOCONVERSION PRODUCTS, TECHNOLOGY, AND ECONOMIC ANALYSIS
}

E.T. Premuzic, M.S. Lin, H. Lian, W.M. Zhou, and J. Yablon

\author{
Biosystems and Process Sciences Division \\ Department of Applied Science \\ Brookhaven National Laboratory \\ Upton, NY 11973
}

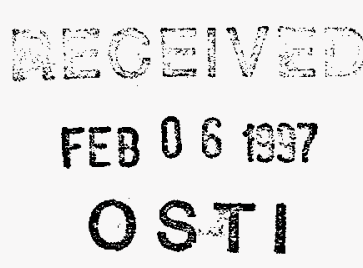

March 1996

Fifth International Symposium on the Biological

Processing of Fossil Fuels

Madrid, Spain

March 19-22, 1996

DISTRBSUTOS OF THS DOGUMERT 15 UMUMTED

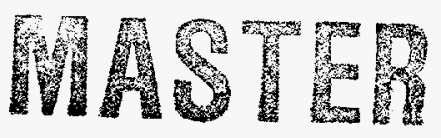

n7

This research was performed under the auspices of the U.S. Department of Energy under Contract No. DE-AC02-76CH00016.

DISCLAIMER

\begin{abstract}
This report was prepared as an account of work sponsored by an agency of the United States Government. Neither the United States Government nor any agency thereof, nor any of their employees, makes any warranty, express or implied, or assumes any legal liability or responsibility for the accuracy, completeness, or usefulness of any information, apparatus, product, or process disclosed, or represents that its use would not infringe privately owned rights. Reference herein to any specific commercial product, process, or service by trade name, trademark, manufacturer, or otherwise does not necessarily constitute or imply its endorsement, recommendation, or favoring by the United States Government or any agency thereof. The views and opinions of authors expressed herein do not necessarily state or reflect those of the United States Government or any agency thereof.
\end{abstract}




\section{DISCLAMMER}

Portions of this document may be illegible in electronic image products. Images are produced from the best available original document. 


\title{
THE USE OF CHEMICAL MARKERS IN THE EVALUATION OF CRUDE OIL BIOCONVERSION PRODUCTS, TECHNOLOGY, AND ECONOMIC ANALYSIS
}

\author{
E.T. Premuzic, M.S. Lin, H. Lian, W.M. Zhou, and J. Yablon \\ Biosystems and Process Sciences Division \\ Department of Applied Science \\ Brookhaven National Laboratory \\ Upton, New York 11973
}

\begin{abstract}
Experimental data gathered over the past several years show that the interactions of microorganisms with crude oils are variable and depend on the microbial species and the chemical composition of crude oils. Systematic studies of chemical mechanisms by which selected microorganisms react with crude oils have led to the identification of biochemical markers characteristic of the interactions of microbes with oils. These biomarkers belong to several groups of natural products ranging from saturate and polyaromatic hydrocarbons containing heterocyclics to organometallic compounds. Chemical marker analyses indicate that the interaction of microbes with crude oils involves multiple chemical reactions resulting from the biochemical interactions between microbes and oils. Different interactions may influence the efficiency of processes in which single or mixed microbial species are used for the oil treatment and may also suggest possible combinations of biological and chemical technologies. Further, the biochemical conversions of oils can be monitored by these chemical markers, which is particularly useful in the optimization of biochemical processing, cost efficiency, and engineering studies. Recent results from these studies will be discussed.
\end{abstract}

\section{Introduction}

Extensive studies dealing with the biochemical interactions of certain microorganisms (thermophilic and thermoadapted) on selected types of crude oils at elevated temperatures and pressures have shown that as a consequence of microbial action significant chemical changes occur in the composition of crude oils ${ }^{1-7}$.

Analysis of data generated from the studies of biochemical action of several species of microorganisms on crude oils from California, Alabama, Arkansas, Wyoming, Alaska, and Venezuela show that biotreatment causes, (1) emulsification, (2) acidification, (3) qualitative and quantitative changes in the light and heavy fractions of crudes, (4) decrease in organic sulfur content and chemical changes in oil fractions containing sulfur compounds, (5) decrease in organic nitrogen content with concurrent biochemical conversion of polar nitrogen containing compounds, (6) decrease in the concentration of trace metals, and $(7)$ the qualitative and 
quantitative changes in the hydrocarbon composition depend on the microbial species and the chemistry of the crudes. There is also a distinction between "biodegraded" and "bioconverted" oils. The former term is more suitable for changes which occur under natural conditions over geological periods of time, and the latter is more applicable to changes brought about by deliberately introduced microorganisms acting over short periods of time. Further, preliminary results indicate that the introduced microorganisms may become the dominant species in the bioconversion of oils ${ }^{3}$. These studies have also generated information which supports the view that the biochemical interactions between crude oils and microorganisms follow distinct trends characterized by a group of chemical markers. Such markers are useful in the prediction of bioprocessing efficiency prior and during the biochemical treatment of crudes regardless of upstream or downstream applications. Further, the microbial species considered in these studies use predominantly indigenous matter as their energy source, which implies that simultaneous intra- and inter- molecular chemical interactions must be involved resulting in multiple chemical effects. In such complex chemical reaction mixtures, the use of chemical (biochemical) markers has obvious advantages. Systematic monitoring, analysis and characterizations of chemical markers allows us to follow a number of process variables such as kinetics, yields, economics, and others essential to the development and application of the bioprocesses in either oil recovery or oil upgrading technology. Several biochemical markers of diagnostic significance have been identified. These include total distribution of hydrocarbons, organic sulfur and nitrogen compounds, organometallic compounds, as well as total sulfur, nitrogen and trace metal contents. Furthermore, corroborative evidence of chemical changes can also be obtained from the distribution of asphaltenes, saturates, aromatics, and resin contents of crudes. To a certain extent, these markers resemble a group of compounds, known as "biomarkers" used in petroleum exploration, source rock and reservoir correlations, as well as maturation and degradation studies 8 , .

\section{Materials and Experimental}

Growth of microorganisms, their use as biocatalysts experimental conditions, protocols, spectroscopies, and chemical analyses have been reported in detail elsewhere ${ }^{1,3,5}$ (and references therein) and will not be discussed here. Economic and engineering analysis were carried out by using one chemical marker, e.g. sulfur for the design of a desulfurization plant. A ten year life span of the plant has been assumed and the total capital investment, manufacturing costs and payback period calculated accordingly ${ }^{10}$. Any variation and modification of the referenced procedures is noted in the bulk of the text.

\section{Methods, Results, and Discussion}

The use of "molecular fossils," i.e. organic natural products originally derived from living organisms, whose molecular structures have persisted over geological time, in the exploration and correlation of petroleum, petroleum source rocks, sediments, and sedimentary organic matter has been successful over the past several years ${ }^{8}$. An extensive database is now available for comparative studies. The experience gained also stresses the importance of using several types of markers for correlational purposes. Analogous to the use of molecular fossil markers, the 
current information regarding the use of chemical markers as correlational and diagnostic tools in the study of biochemical processing of oils by different microbial species also points to the usefulness of the multiple chemical markers analysis.

For example, analytical data shown in Tables 1-4 indicate that the overall effect on the chemical markers due to the bioconversion of oils is a decrease in the concentrations of sulfur, nitrogen, vanadium, and nickel. However, this effect is not uniform and varies with the oil and the biocatalyst used, emphasized in Table 4, in which Cerro Negro, a heavy crude, was treated with several different biocatalysts. The chemical properties of the oils used in these experiments also differ and have to be considered.

For the purposes of this discussion, the four oils (Tables 1-4) which include two Venezuelan and two Californian oils, will be compared to another set of Monterey, California oils, A836, A837, and $\mathrm{A}_{851^{3}}$. All of these oils are heavy with ${ }^{\circ} \mathrm{API}$ gravities ranging from 12 to 19 . The hydrocarbon distribution for all of the oils to be considered is given in Table 5. It is to be emphasized that the analytical methods used, i.e., chromarod and solvent/column chromatography, generate results which can only be compared qualitatively because of the use of different solvents and fractionation techniques. These techniques are sensitive to the effects of solvents on the relative concentration of saturates, aromatics, resins, and asphaltenes. However, regardless of the solubility bias, the relative distribution of major fractions reflects the history of the oil. Low ${ }^{\circ} \mathrm{API}(<20)$ gravity oils are low in gasoline and high in residuum, which means that as the oils become heavier, the $\mathrm{H} / \mathrm{C}$ ratios decrease as the oils change from light to dark heavy oils, while the NSO/C ratios increase and the oils become richer in asphaltenes. Thus, the heavier fractions of oils are richer in resins, asphaltenes, and polar compounds containing heteroatoms $(\mathrm{O}, \mathrm{N}, \mathrm{S})$ and metals. Chemically, this also means changes in the concentration and distribution of paraffinic, naphtenic, and aromatic compounds with a progressive increase in the concentration of polyaromatic and heterocyclic compounds. The highest concentration of the heterocyclic compounds is found in resins and asphaltenes. Further, these condensed polyaromatic chemical structures contain free radical sites with highly reactive unpaired electrons. These sites are involved in complexation of metals as well as inter- and intramolecular reactions and molecular rearrangements. The polarity of asphaltic structures plays also an important role in hydrogen bonding and charge transfer complexes. The combined effects of the mentioned functionalities, i.e. those due to reactions such as complexing at $\mathrm{O}, \mathrm{N}, \mathrm{S}$ sites and those due to unpaired electron rearrangements, such as redox reactions, affect also viscosity and micellar structures. These chemical properties play decisive roles in the behavior of crude oils in reservoirs as well as their behavior in upstream and downstream processing. It is these properties that also influence the biochemistry associated with the interactions of microorganisms and crude oils. Mechanistically, microorganisms can then be considered as catalysts entering colloidal, micellar and molecular solutions which react with active sites ${ }^{1}$ initiating a dispersion of micellar organization which leads to a "depolymerization" of the heavy crude polymer as shown in Figure 1, where the dark dots represent heteroatoms and other reactive sites. Such multiple reactions are analogous to the well studied mechanisms of microbial interactions with particulate matter, mineral surfaces, membranes, and other chemical surfaces involving active sites ${ }^{14,15,16}$. The chemical markers discussed in this paper represent both 
extent of the heaviness of the crude and the degree of biochemical conversion of the crude. For example, the oils listed in Table 5, in addition to being heavy, have other common characteristics. Monterey A851, a California crude and Cerro Negro, a Venezuelan crude are heavy because they are "biodegraded," meaning, biodegraded over geological periods of time under reservoir conditions. Venezuelan Boscan crude and the California crudes, Monterey A836, A837, and OSC are heavy, because they are immature. The sample of Midway Sunset Crude, also a California heavy crude has been subject to secondary steam recovery which contributed to chemical alteration ${ }^{12}$. Although these oils are complex mixtures representing different types of oils they all fall into definable categories. Chemically and biochemically caused changes in these categories involve multiple and simultaneous reactions within a complex matrix, which follow distinct trends that can be followed by chemical markers. Thus, gas chromatographymass spectrometry analysis (GC-MS) (Figure 2) of M851 treated with three different biocatalysts shows an enrichment in lighter hydrocarbons as well as an overall redistribution of hydrocarbons. Because the data have been generated under identical experimental conditions using different microorganisms, the bioconversion of the biodegraded M851 oil by BNL-NZ-3 appears to be more efficient. Table 6 shows the efficiency of organic sulfur removal by several different microorganisms on the same Monterey 851 biodegraded oil. It is to be noted that the changes in the sulfur concentration are due to the introduced microorganisms and not due to indigenous microorganisms responsible for the original formation of the heavy biodegraded oil. The induced bioconversion of the four major hydrocarbon fractions of this oil (shown in Table 7) compared to the control (i.e. M851 untreated) leads to changes in the relative concentrations of saturates, aromatics, resins and asphaltenes. The overall trend is an increase in saturates, a decrease in aromatics, and an increase in resins. Comparable results for OSC and MWS using two of the seven biocatalysts used in the present study are shown in Table 8. It is to be noted that the concentration of asphaltenes decreases except in the BNL-NZ-3/M851, BNL-TH$31 / \mathrm{M} 851$, and BNL-4-22/OSC cases. Since this increase is very small relative to changes in other components, this exception may be within the experimental error. Further studies will clarify whether these exceptions might also be due to the initial extent of activation in the bioreactor or are due to some chemistry peculiar to the particular biosystem used. Corresponding comparative GC-MS analyses of the immature OSC and steam treated MWS crudes are given in Figure 3 and 4 . Consistent with previous results, bioconversion of these oils leads to an enrichment in lighter hydrocarbons and an overall redistribution of the hydrocarbons, as shown by the peak clusters at retention times of 20-25 minutes and 35-40 minutes. Chromatographic analyses of organic sulfur compounds using a sulfur specific detector, Figure 5, shows a decrease in the total signal consistent with the analyses given in Table 1. Although OSC is a high sulfur content oil $(4.4 \%)$ while MWS is much lower $(1.1 \%)$ in sulfur, the overall lowering in concentration of organosulfur compounds and a concurrent redistribution of residual organic sulfur compounds is significant. These changes have been accomplished in a single pass per batch process, an important consideration in the application of the biochemical upgrading of heavy crudes to be discussed later. Extension of the chemical marker analyses to major fractions of crude oils emphasized further the importance and the utility of the markers as diagnostic signals in process evaluation and the understanding of underlying mechanisms. For example, the pentane precipitation of the OSC asphaltenes concentrates the heavy, nonvolatile components, therefore, the precipitate requires pyrolysis (Py)-GC-MS to analyze for hydrocarbon as shown in Figure 6. Even in this heavy fraction, the relative increase in the light components after the 
biochemical treatment with BNL-4-22 and BNL-4-23 is clearly evident. Corresponding sulfur specific analysis (Figure 7) shows that major changes in organosulfur composition have also occurred.

These results are consistent with those obtained for non-fractionated, whole oils (Figures 3-5) and contribute further evidence that biochemical reactions occur in the heavy, polar fractions of the oils. Similar experimental evidence has also been gained from analogous nitrogen studies as shown in Figures 8 and 9. These experimental data have been generated under identical conditions and, therefore, can be compared directly. Lowering in the total nitrogen content is evident by the absence and/or decrease in the intensity of chromatographic signals. Although the chromatograms are very complex and require detailed analysis, the nitrogen containing compounds follow an analogous pattern to that shown by the corresponding analysis of hydrocarbons and sulfur containing compounds (Figures 3-5), i.e. redistribution in the composition and an enrichment in the lower molecular weight components.

Experimental data discussed in the above paragraphs show that selected chemical markers characterize the chemical nature and the extent of crude oil bioconversion and, therefore, could be useful in the assessment of a technology based on the biochemical processing of crudes. As an example of this application, preliminary data generated by the operation of a laboratory scale plant which has been designed to upgrade low grade crude oils by biochemical processing will be discussed. A block diagram for this process is shown in Figure 10. In this process, a fifty-five gallon bioreactor has been used. There are two major parts to this process. The first part is a biochemical batch process in which the oil and the biocatalysts are mixed by concurrent pumping through a mixer to make an oil-in-water emulsion. The process is set to run in a batch mode and a thirty-six hour, fifty cycle pass. The second part deals with the processing of waste products. In this particular example, the aqueous phase is separated from oil by a sedimentation centrifuge although other de-emulsification techniques can be used. The aqueous phase is then further treated using several available technologies, such as co-precipitation and/or absorption of metals and by-products. In these experiments, a single chemical marker, i.e. the total concentration of sulfur before and after bioprocessing has been used for the economic and technical analysis of the process.

In the scaled up projection of the plant, a ten year life span of the plant was assumed and for the cost analysis three steps have been considered. The first step was to obtain the total capital investment $^{10}$. Detailed cost estimates for each unit have been derived from published data ${ }^{10,17}$. The second step was to calculate manufacturing costs. In this step combined ECI and Ulrich methods ${ }^{10,18}$ have been used. The third step was to calculate the net present value and pay back period which relates to the interest rates, i.e. the cost of borrowed money ${ }^{10,17}$. A heavy, $3 \%$ sulfur crude oil has been used as the test case in which varying sulfur removal efficiencies have been analyzed. In this particular case, as shown in Figure 11, regardless of the amount of sulfur removed, e.g. from $33 \%$ to $45 \%$, the annual net profit increases with the decrease in the reaction time. The analysis described in Figure 12 shows that the annual net profit also increases as a function of an increase in the level of sulfur removal from the oil at different reaction rates. The combined data given in the two figures clearly indicate that in order to maximize the annual net profit, it is necessary to shorten the reaction time and simultaneously increase the amount of 
sulfur removed from the oil. Using this approach, a cost-efficiency analysis has been carried out yielding results which can be applied directly to the design and optimization of biochemical processes using a single chemical marker such as sulfur. In the scenario represented by Figure 13 , a case which only uses in-house funds for capital investment, is compared to two cases which involve moneys from outside financial groups at interest rates of $10 \%$ and $15 \%$. Only the case with in-house funding shows a pay back period of 3.4 years with a net present value of $\$ 10.7$ million, assuming that the plant will operate for ten years to reach its anticipated life time. The other options are even less attractive. However, if the reaction time can be reduced to 36 hours and at the same time the sulfur removal from the oil increased to $40 \%$, then the pay back period can be reduced to 1.9 years. In this case, the net present value after operating for 10 years becomes $\$ 22.4$ million, without borrowing any moneys from financial houses (Figure 14). Using such cost analyses enables us to define laboratory research and development protocols which identify the parameters such as the reduction in the reaction times and the amount of sulfur removal that have to be optimized in order to improve the overall cost-efficiency of the process. Concurrent with this strategy, further cost-efficiency can be accomplished by tailoring the process(es) to end product users such as the utilities, refineries, and others. For example, this may be accomplished by modifying process variables for nitrogen and trace metals removal. In all cases, this R\&D strategy uses chemical markers in the development and application of new upstream and downstream oil processing operations.

\section{Conclusions}

The use of chemical markers in the monitoring of the interactions between different microorganisms and various crude oils allows us to determine the efficiency of the biochemical conversion of the crudes. The biochemical mechanisms by which microorganisms interact with crude oils based on the current experimental evidence appear to involve reactions at heteroatoms, i.e. $\mathrm{N}, \mathrm{S}, \mathrm{O}$, and organometallic compounds and other active sites leading to:

1. Reduction in sulfur concentration $(20 \%-45 \%)$

2. Reduction in nitrogen concentration ( $15 \%-45 \%)$

3. Reduction in trace metals concentration $(16 \%-60 \%)$

4. Conversion of heavy fraction of crudes into lighter fractions

5. Optimum reaction conditions depend on microbial species used and the chemical composition of the oil.

6. Chemical markers are useful in the prediction of the cost-efficiency of a process and simultaneously guide the R\&D effort in the process optimization and the development of biochemical technology for upgrading of low grade oils. 


\section{Acknowledgments}

This work is supported by the U.S. Department of Energy, Division of Fossil Fuels, under Contract No. AS-219-ECD, and Contract No. DE-AC02-76CH00016 with the U.S. Department of Energy. We wish to express our gratitude to Ernie Zuech of the U.S. DOE, Bartlesville office for the supply of OSC oils and the Synfuels Research Corporation and the Santa Fe Energy Resources, Inc. of Houston for the supply of MWS oil. We also wish to acknowledge Mark McCaffrey (formerly of Chevron) for the samples of M851, 836, and 837 oils, Yao Lin of Brookhaven National Laboratory for the graphic materials and T. F. Yen, and his group at the University of Southern California, CA for the chromarod analyses and valuable discussions.

\section{References}

1. Premuzic, E.T., Lin, M.S., and Manowitz, B.: "The Significance of Chemical Markers in the Bioprocessing of Fuels," Fuel Processing Technology (1994) 40, 227-239.

2. Lin, M.S., Premuzic, E.T., Yablon, J.H., and Zhou, W.M.: "Biochemical Processing of Heavy Oils and Residuum," J. of Applied Biotechnology and Biochemistry (1995), In press.

3. Premuzic, E.T., Lin, M.S., Racaniello, L., and Manowitz, B.: Microbial Enhancement of Oil Recovery--Recent Advances, Proceedings of the International Conference on Microbial Enhanced Oil Recovery, Elsevier Science Publishers, Amsterdam (1993) 37-54.

4. Premuzic, E.T., Lin, M.S., Jin, J.Z., Manowitz, B., and Racaniello, L.: Biochemical alteration of crude oils in Microbial Enhanced Oil Recovery, The Minerals, Metals, and Materials Society, Warrandale, PA (1993) 401-413.

5. Premuzic, E.T. and Lin, M.S.: Microbial Enhancement of Oil Recovery--Recent Advances, Proceedings of the 1990 International Conference on Microbial Enhanced Oil Recovery, Elsevier Science Publishers, Amsterdam (1991) 277-296.

6. Premuzic, E.T. and Lin, M.S.: Interactions Between Thermophilic Microorganisms and Crude Oils, Recent Developments, Res. Cons. and Recyc. 5, (1991) 277-284.

7. Premuzic, E.T.: Biochemically Enhanced Oil Recovery and Oil Treatment. U.S. Patent No. 5,297,025 (1994). Premuzic, E.T. and Lin, M.: Process for producing modified microorganisms for oil treatment at high temperatures, pressures, and salinity. U.S. Patent No. 5,492,828 (1996).

8. Peters, K.E. and Moldowan, J.M.: The Biomarker Guide," Prentice Hall, New York (1993) 363.

9. Hunt, J.M.: Petroleum Geochemistry and Geology, W.H. Freeman \& Co., San Francisco, 1979 , Ch.3.

10. Ulrich, G.D.: A Guide to Chemical Engineering Process Design and Economics, John Wiley and Sons, New York (1994) Chs. 5, 6, and 8.

11. Lian, H.J., Lee, C., and Yen, T.F.: Asphaltene Particles in Fossil Exploration Recovery, Refining, and Production Processes, Plenum Press, New York (1994) 229-237.

12. Reynolds, J.G.: "Personal Communication to EP," Lawrence Livermore National Laboratory (1995).

13. Yen, T.F.: Encyclopedia of Polymer Science and Engineering Index Volume, 2nd Edition, John Wiley and Sons, New York (1990) 1-10. 
14. Weinberg, E.D.: Microorganisms and Metals, Marcel Dekker, Inc. New York (1977) 492.

15. Ehrlich, H.L. and Holmes, Eds.: Workshop on Biotechnology for the Mining, MetalRefining, and Fossil Fuel Processing Industries, John Wiley and Sons, New York (1986) 386.

16. Atlas, R.M.: Petroleum Microbiology, Macmillan Inc., New York (1984) 692.

17. Perry, J.H. and Chilton, C.H.: Chemical Engineers' Handbook, 6th Edition, McGraw-Hill, New York (1993).

18. Dounias, G.A. and Stavropoulos, K.D.: "Economic Feasibility of Biochemical Upgrading of Heavy Crudes," (1995) Final Report to BNL. 
Table 1 Variations in the concentrations of Sulfur as a function of Biocatalyst Treatment of four crudes: Boscan (BOS), Cerro Negro (CN), Midway Sunset Oil (MWS) and Offshore California (OSC)

\begin{tabular}{cccc}
\hline \multicolumn{3}{c}{ Sulfur } \\
\hline Oil & $\begin{array}{c}\text { Initial conc. of } \\
\text { S \% }\end{array}$ & $\begin{array}{l}\text { Treatment } \\
\text { Biocatalyst }\end{array}$ & $\begin{array}{c}\text { Reduction in } \\
\text { conc. of S \% }\end{array}$ \\
\hline BOS & 5.49 & BNL-4-22 & 25 \\
CN & 4.37 & BNL-4-23 & 25 \\
CN & 4.37 & BNL-4-24 & 29 \\
MWS & 1.1 & BNL-4-23 & 50 \\
OSC & 4.4 & BNL-4-23 & 45 \\
\hline
\end{tabular}

Table 2 Variations in the Concentration of Nitrogen as a Function of Biocatalyst Treatment

\begin{tabular}{cclc}
\hline & \multicolumn{2}{c}{ Nitrogen } & \\
\hline Oil & $\begin{array}{c}\text { Initial Conc. } \\
\text { of } \mathbf{N} \%\end{array}$ & $\begin{array}{l}\text { Treatment } \\
\text { Biocatalyst }\end{array}$ & $\begin{array}{c}\text { Reduction in } \\
\text { conc. of } \mathbf{N} \%\end{array}$ \\
\hline MWS & 0.79 & BNL-4-22 & 25 \\
MWS & 0.79 & BNL-4-23 & 15 \\
OSC & 0.66 & BNL-4-22 & 20 \\
OSC & 0.66 & BNL-4-23 & 45 \\
\hline
\end{tabular}

Table 3 Variation in the concentration of Nickel and Vanadium as a function of Biocatalyst Treatment

\begin{tabular}{ccccc}
\hline & \multicolumn{4}{c}{ Nickel and Vanadium } \\
\hline \multirow{2}{*}{ Oil } & Metal & $\begin{array}{c}\text { Initial Conc. } \\
\text { ppm }\end{array}$ & $\begin{array}{c}\text { Treatment } \\
\text { Biocatalyst }\end{array}$ & $\begin{array}{c}\text { Reduction in conc. } \\
\text { of Metal \% }\end{array}$ \\
\hline CN & Ni & 247 & BNL-4-23 & 35 \\
& V & 494 & BNL-4-23 & 58 \\
MWS & Ni & 63 & BNL-4-22 & 19 \\
& V & 24 & BNL-4-22 & 20 \\
MWS & Ni & 63 & BNL-4-23 & 25 \\
& V & 24 & BNL-4-23 & 36 \\
OSC & Ni & 80 & BNL-4-22 & 28 \\
& V & 202 & BNL-4-22 & 33 \\
OSC & Ni & 80 & BNL-4-23 & 20 \\
& V & 202 & BNL-4-23 & 16 \\
\hline
\end{tabular}


Table 4 Variation of Nickel and Vanadium contents in Cerro Negro crude as a function of several different Biocatalysts

\begin{tabular}{cccc}
\hline Biocatalyst & Metal & Initial Conc. & $\begin{array}{c}\text { Reduction in conc. } \\
\text { of Metal \% }\end{array}$ \\
\hline BNL-4-24 & $\mathrm{Ni}$ & 247 & 25 \\
BNL-4-24 & $\mathrm{V}$ & 494 & 38 \\
BNL-TH-29+ & $\mathrm{Ni}$ & 247 & 32 \\
BNL-TH-31 & $\mathrm{V}$ & 494 & 57 \\
BNL-2-45+ & $\mathrm{Ni}$ & 247 & 51 \\
BNL-3-26 & $\mathrm{V}$ & 494 & 68 \\
\hline
\end{tabular}

Table 5 Comparison of the heavy crudes

\begin{tabular}{|c|c|c|c|c|c|c|c|}
\hline Oil & OSC $^{*}$ & MWS* & $\mathrm{A836* \star}$ & $\mathbf{A 8 3 7 ^ { * * }}$ & A851* & $\mathrm{CN}^{\star \star}$ & $\mathrm{BOS}^{\star \star *}$ \\
\hline Saturate \% & 17.3 & 19.2 & 10.3 & 12.8 & 19.2 & 11.7 & 10.7 \\
\hline Aromatic \% & 39.1 & 44.9 & 8.7 & 5.8 & 45.2 & 18.3 & 14.4 \\
\hline Resin \% & 37.4 & 35.3 & 25.0 & 30.4 & 38.9 & 45.0 & 34.8 \\
\hline Asphaltene \% & 6.20 & 2.6 & 56.0 & 51.0 & 4.4 & 25 & 40 \\
\hline
\end{tabular}

* Analyzed by the chromarod method (11)

${ }^{* *}$ Analyzed by solvent and column chromatography method $(3,8)$ 
Table 6 Initial total organic sulfur contents and \% sulfur removed after biotreatment

\begin{tabular}{lcccccccc}
\hline & UTM 851 & BNL-NZ-3 & BNL-TH-31 & BNL-TH-29 & BNL-4-21 & BNL-4-22 & BNL-4-23 & BNL-4-24 \\
\hline Total \% & 1.84 & 1.29 & 1.56 & 1.54 & 1.63 & 1.47 & 1.29 & 1.30 \\
$\%$ S Removed & - & 30 & 15 & 15 & 16 & 20 & 30 & 30 \\
\hline
\end{tabular}

Table 7 Determination of four major fractions by TLC-FID using Chromarods

\begin{tabular}{|c|c|c|c|c|c|c|c|c|}
\hline & UTM 851 & BNL-NZ-3 & BNL-TH-31 & BNL-TH-29 & BNL-4-21 & BNL-4-22 & BNL-4-23 & BNL-4-24 \\
\hline Saturate \% & 19.19 & 23.62 & 22.01 & 24.72 & 32.29 & 28.72 & 34.42 & 29.21 \\
\hline Aromatic $\%$ & 45.15 & 31.64 & 35.27 & 28.62 & 32.04 & 33.87 & 29.72 & 19.59 \\
\hline Resin \% & 31.23 & 38.94 & 37.88 & 43.44 & 32.00 & 33.31 & 32.71 & 38.20 \\
\hline Asphaltene $\%$ & 4.44 & 5.79 & 4.84 & 3.41 & 3.67 & 4.09 & 3.57 & 2.99 \\
\hline
\end{tabular}

UTM 851 = Monterey 851 untreated control

Table 8 Determination of four major fractions by TLC-FID using Chromarods

\begin{tabular}{|c|c|c|c|c|c|c|}
\hline & $\begin{array}{c}\text { Control untreated } \\
\text { OSC }\end{array}$ & $\begin{array}{c}\text { BNL 4-22 } \\
\text { treated OSC }\end{array}$ & $\begin{array}{c}\text { BNL 4-23 } \\
\text { treated OSC }\end{array}$ & $\begin{array}{c}\text { Control } \\
\text { untreated MWS }\end{array}$ & $\begin{array}{c}\text { BNL 4-22 } \\
\text { treated MWS }\end{array}$ & $\begin{array}{c}\text { BNL 4-23 } \\
\text { treated MWS }\end{array}$ \\
\hline Saturate \% & 17.3 & 45.5 & 51.6 & 19.2 & 33.7 & 66.3 \\
\hline Aromatic \% & 39.1 & 18.0 & 20.5 & 44.9 & 29.1 & 11.2 \\
\hline Resin \% & 37.4 & 30.1 & 22.3 & 35.3 & 34.2 & 19.3 \\
\hline Asphaltene $\%$ & 6.20 & 6.43 & 5.65 & 2.60 & 2.97 & 3.18 \\
\hline
\end{tabular}


Heavy Crude "polymer" $\rightarrow \rightarrow$
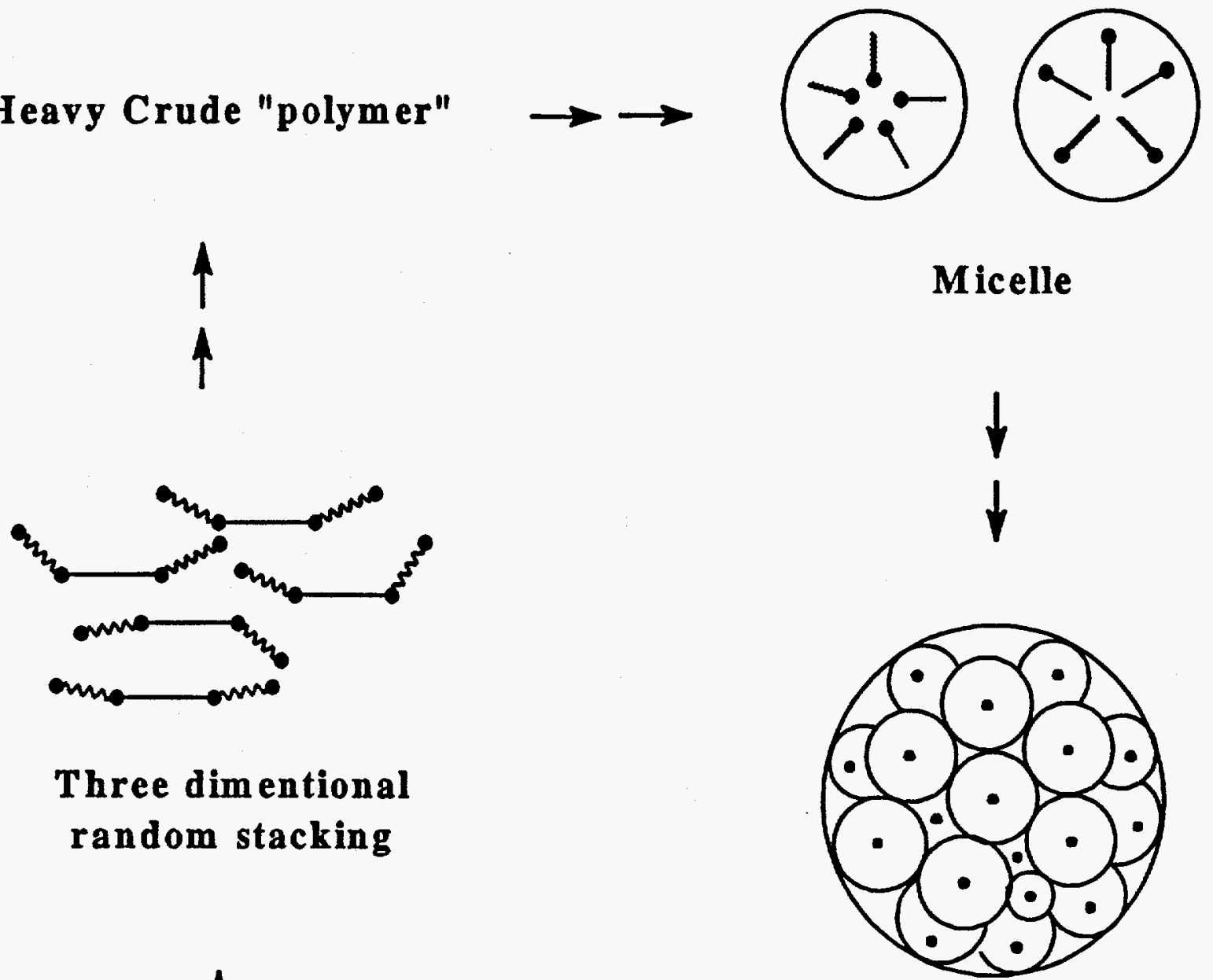

Three dimentional

random stacking

4

Super micelle

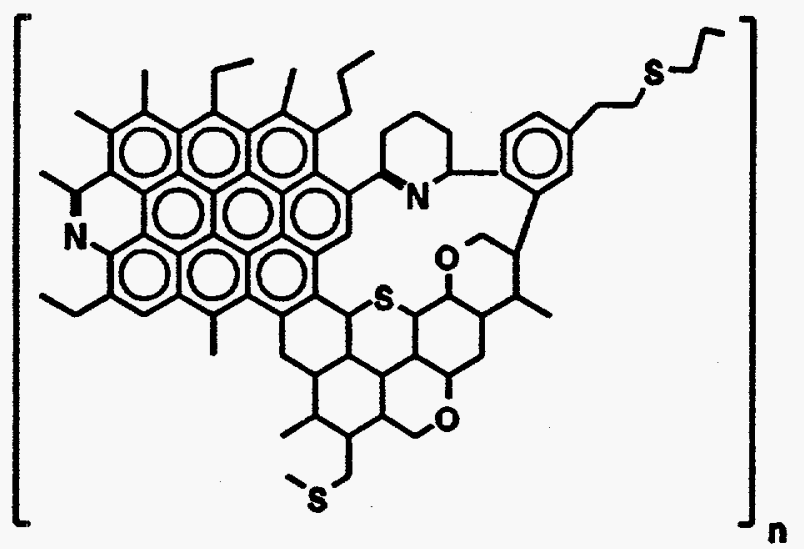

41

41

11

Multiple super micelles

41

Colloidal, micellar,

Schematic Asphaltene Molecule and molecular solutions

Figure 1. Formation of heavy oil fractions from a schematic Asphaltene Molecule (After 9 and 13). Dark circles represent heteroatoms and active sites. 

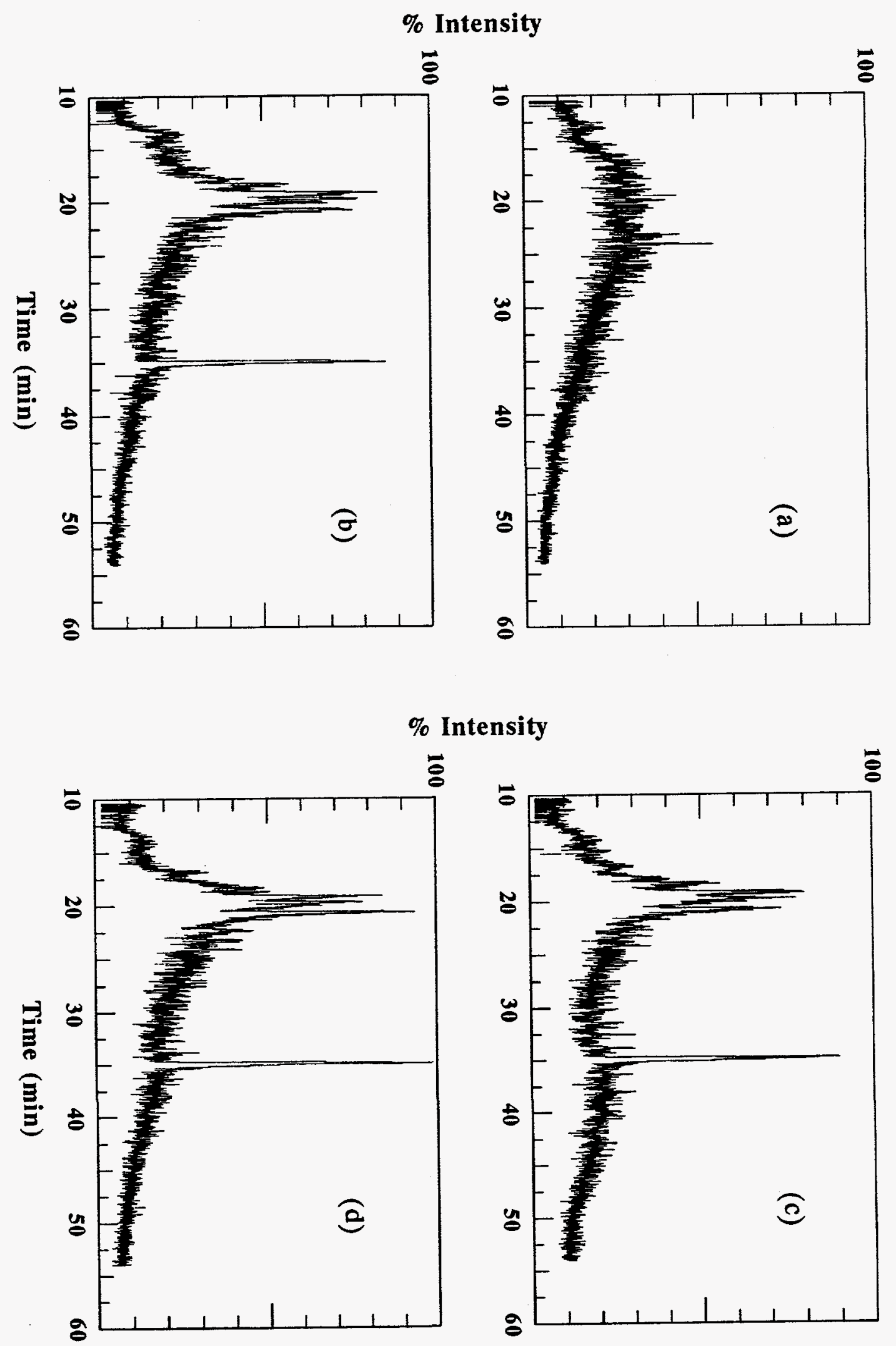

Figure 2. GC-MS analysis M851 M/e 57 gas chromatogram trace of (a) control, (b) treated with BNL-4-22, (c) treated with BNL-4-23, (d) treated with BNL-NZ-3. 


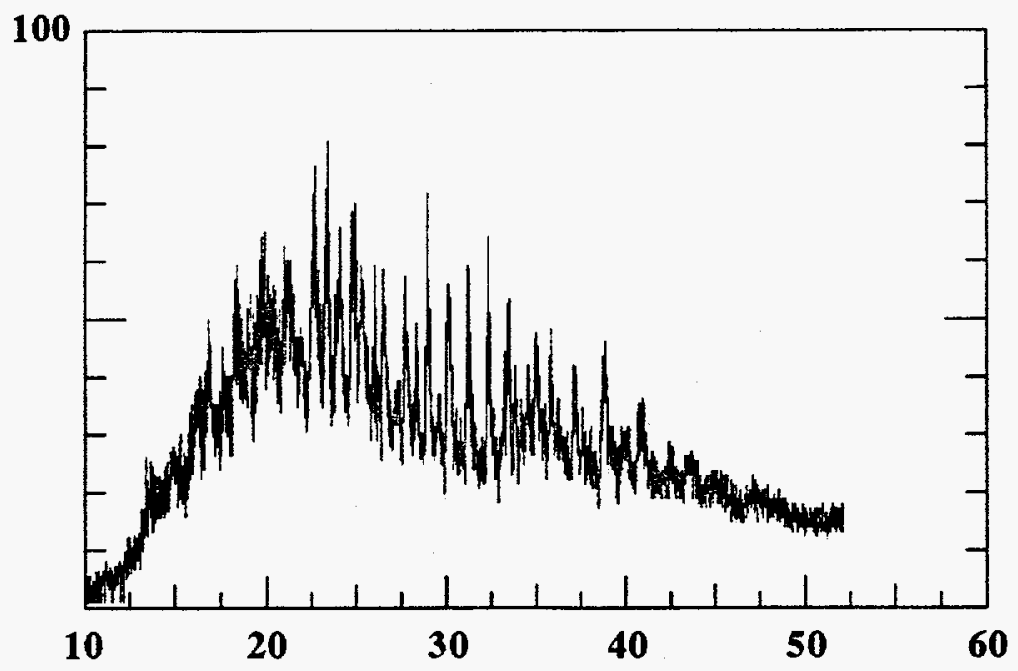

(a)

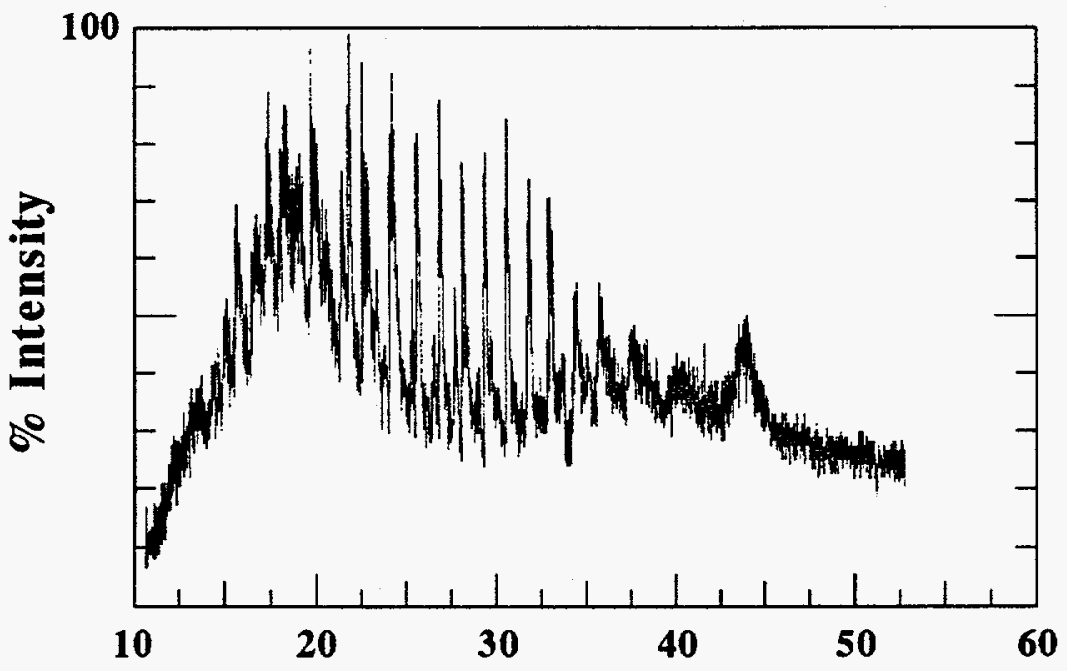

(b)

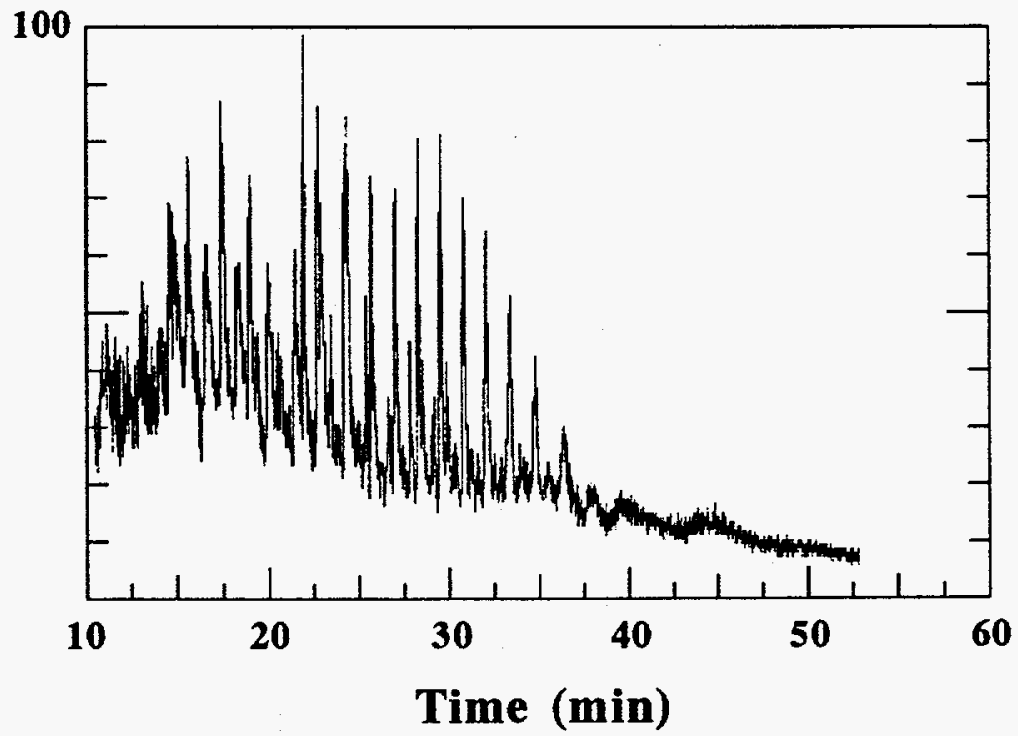

(c)

Figure 3. OSC M/e 57 gas chromatogram trace of (a) treated with BNL-4-22, (b) treated with BNL-4-23, (c) OSC control. 


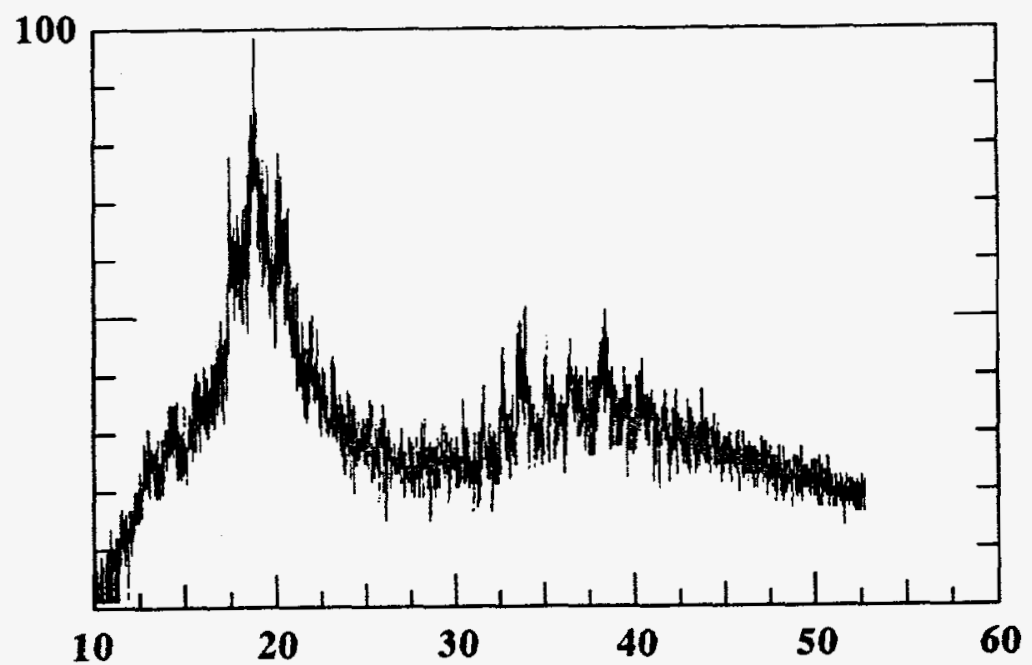

(a)

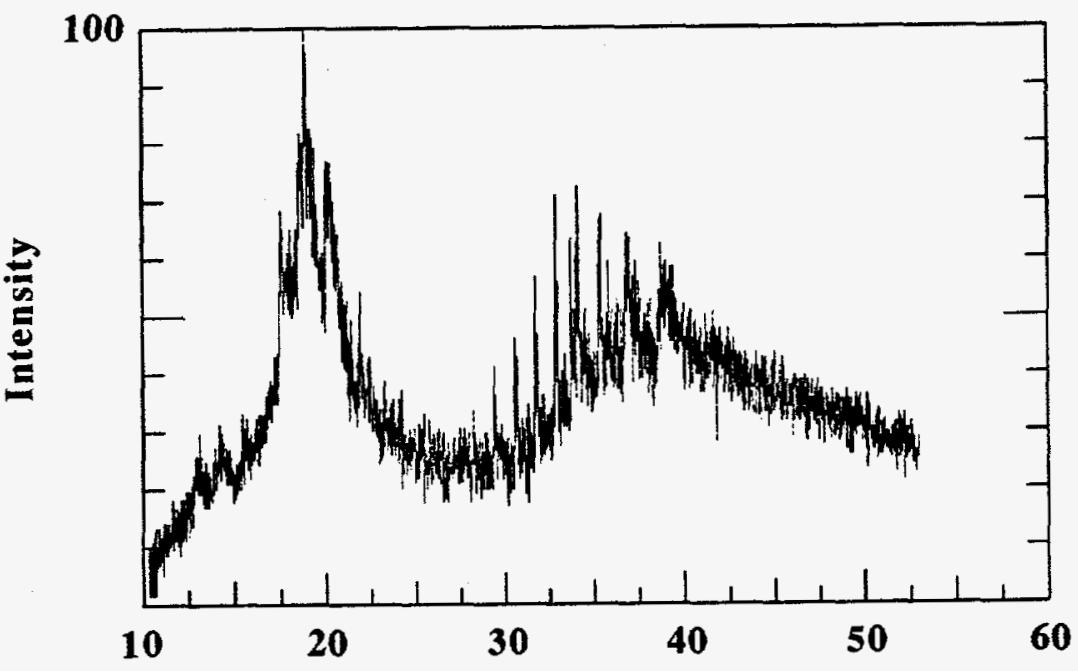

(b)

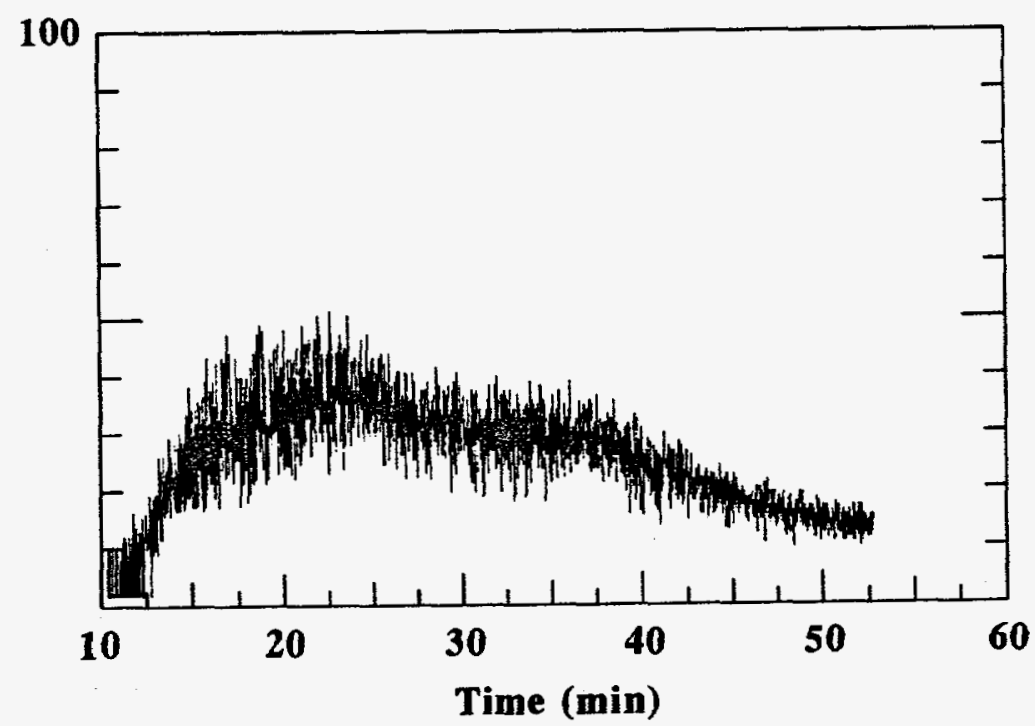

(c)

Figure 4. MWS M/e 57 gas chromatogram trace of (a) treated with BNL-4-22, (b) treated with BNL-4-23, (c) MWS control. 

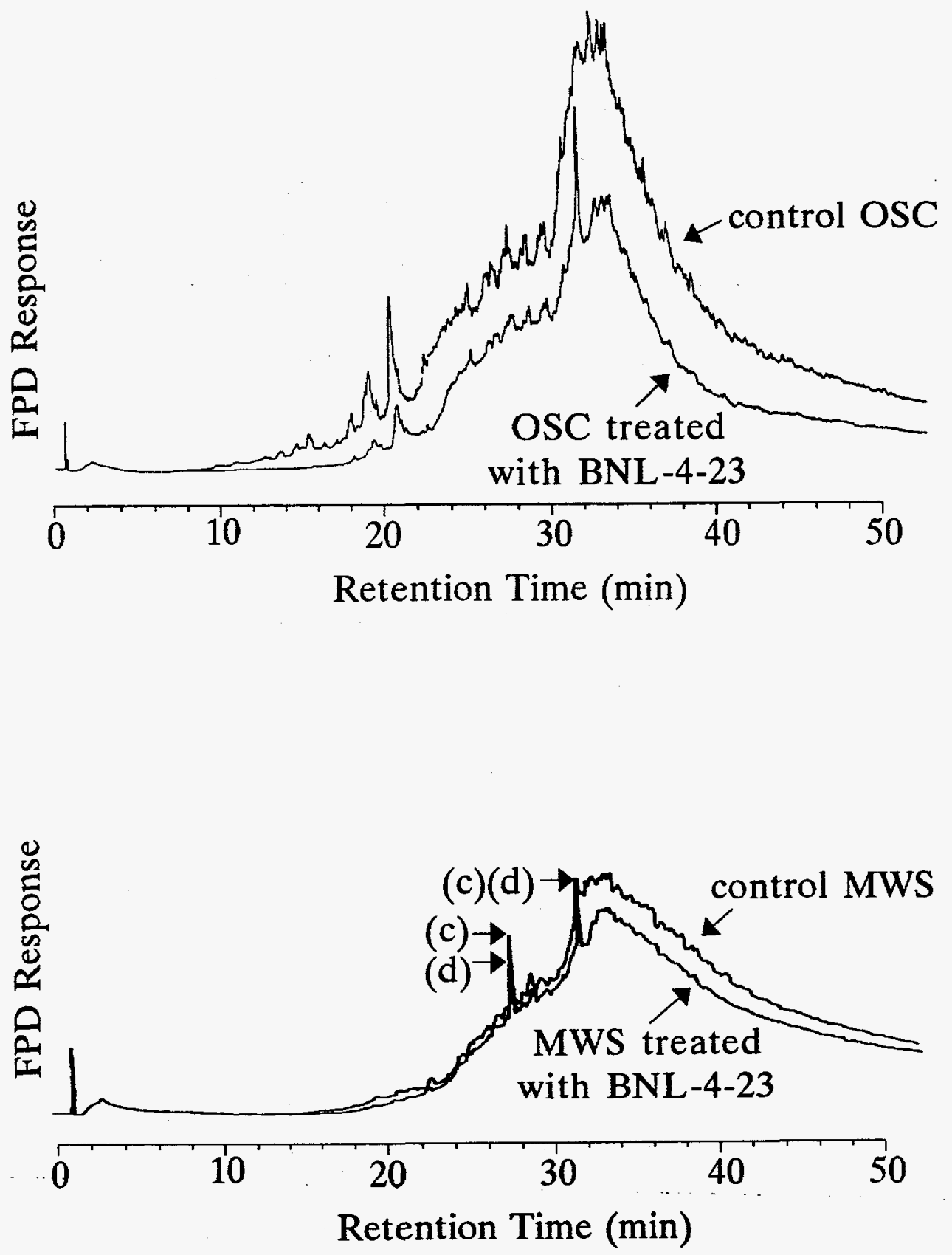

Figure 5. Sulfur specific trace (FPD*) chromatogram of: (a) untreated OSC, (b) OSC treated with BNL-4-23, (c) control MWS, (d) MWS treated with BNL-4-23. *Flame Photometric Detector 


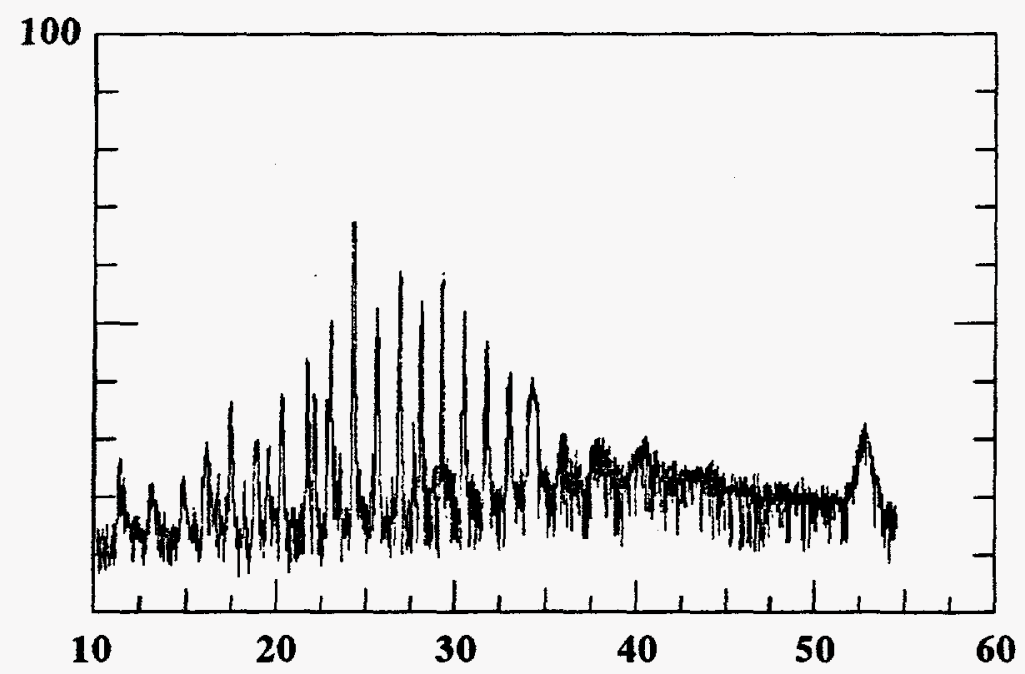

(a)

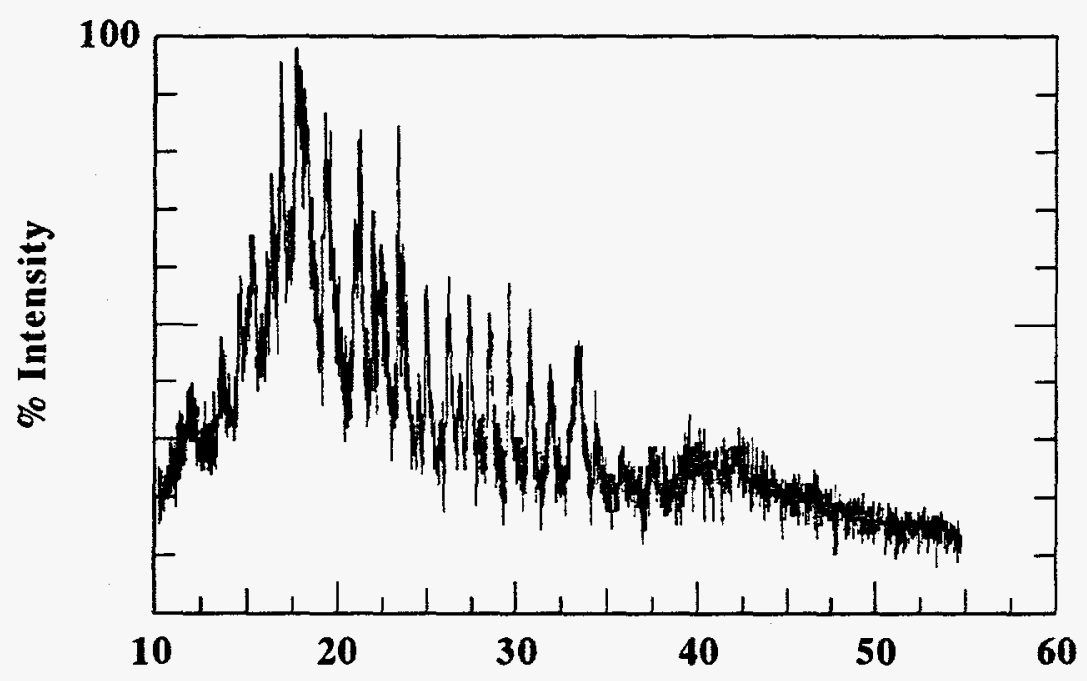

(b)

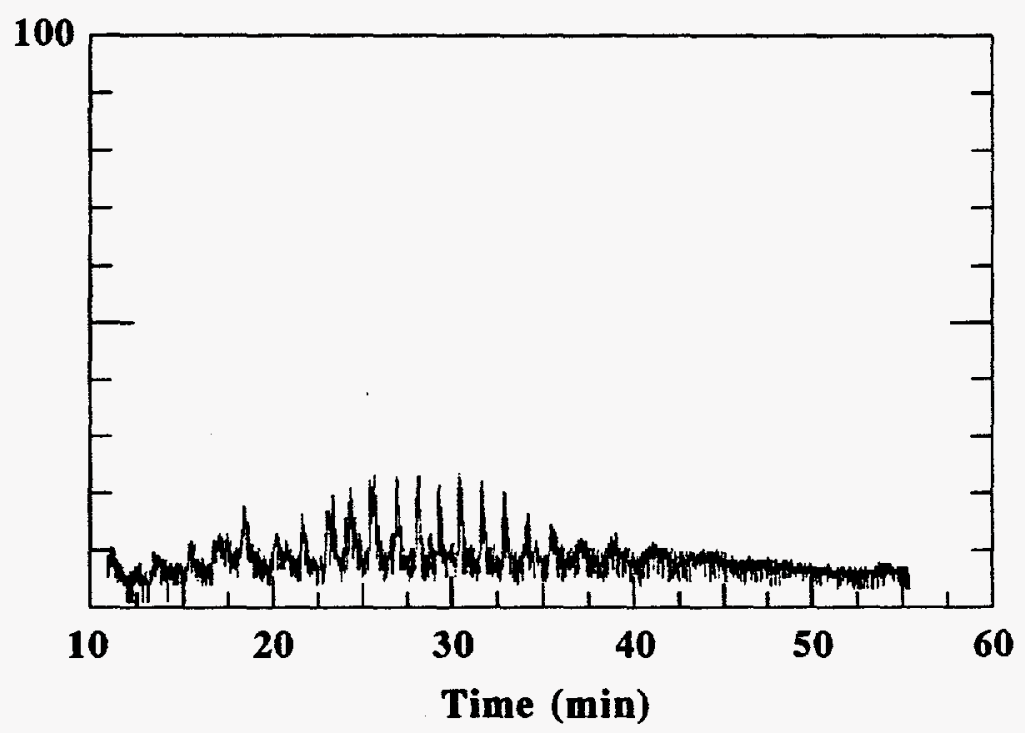

(c)

Figure 6. OSC M/e 57 pyrolysis gas chromatogram of asphaltenes: (a) Treated with BNL-4-23, (b) Treated with BNL-4-22, (c) control. 

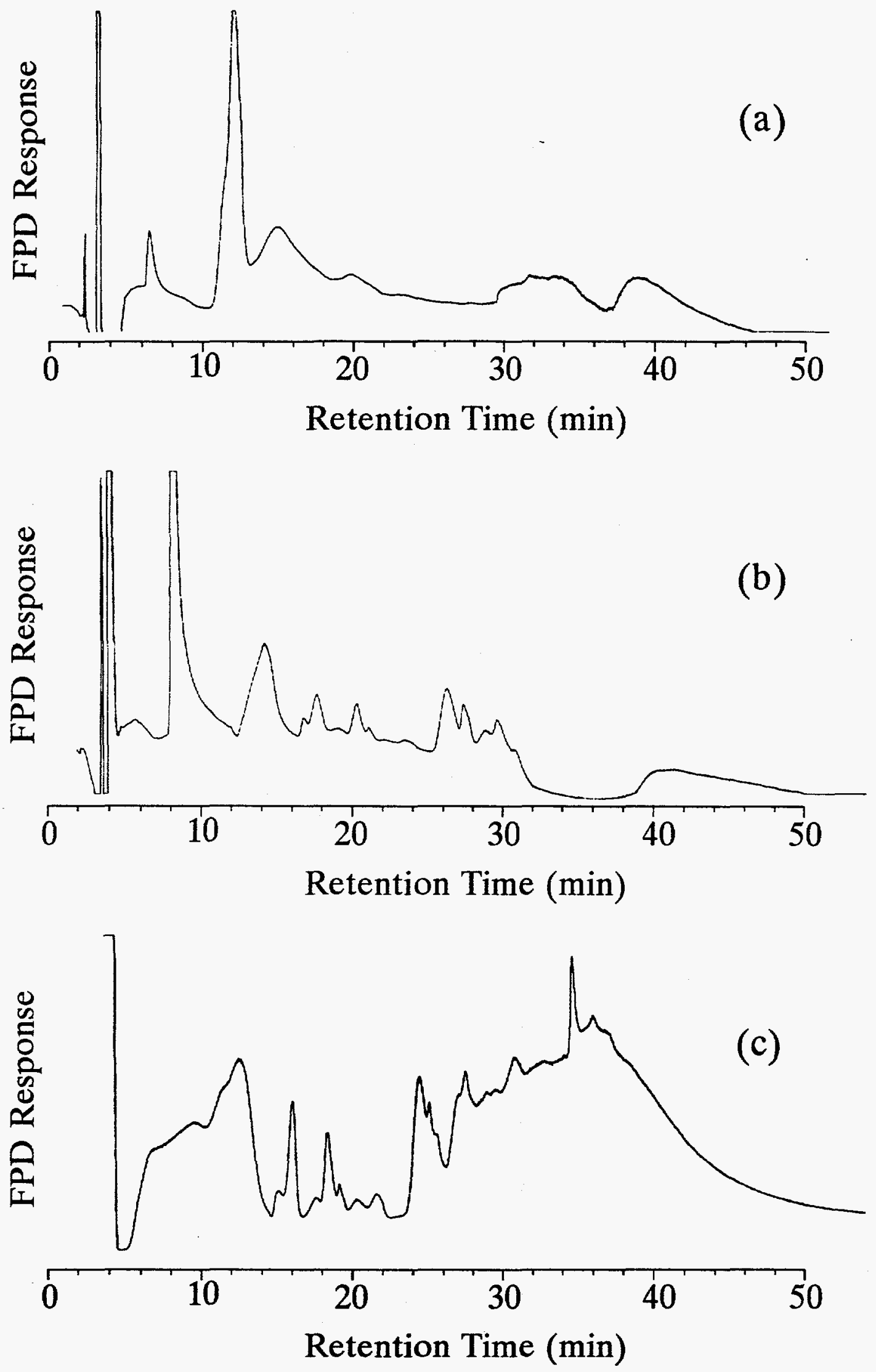

Figure 7. Pyrolysis gas chromatogram of asphaltene from OSC crude. FPD sulfur specific trace: (a) treated with BNL-4-23, (b) treated with BNL-4-22, (c) control OSC. Shorter retention time indicate smaller molecular weight fractions. 


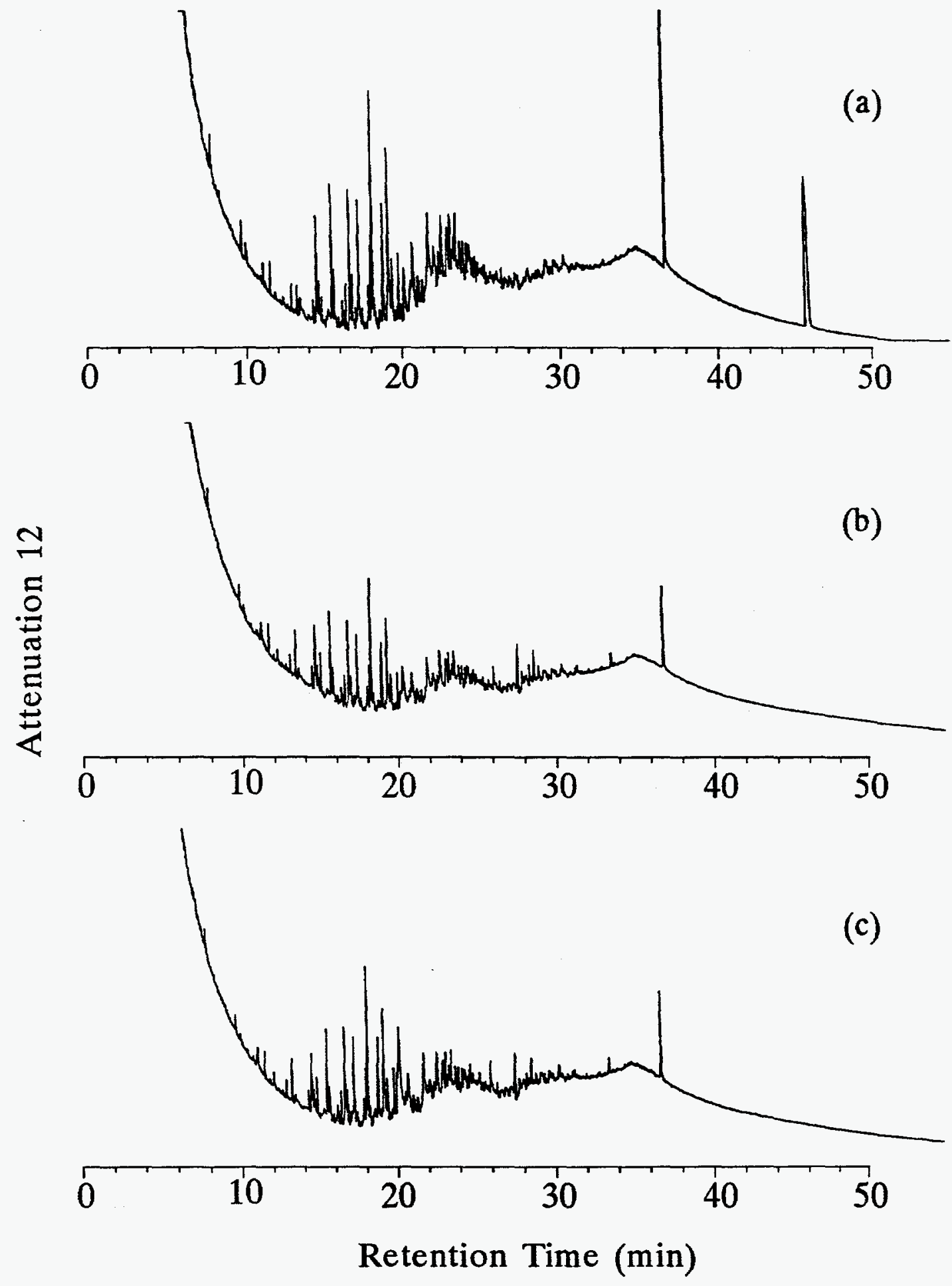

Figure 8. Nitrogen specific trace (NPD*) chromatogram of: (a) untreated OSC, (b) OSC treated with BNL-4-22, and (c) treated with BNL-4-23.

*Nitrogen Phosphorous Detector 

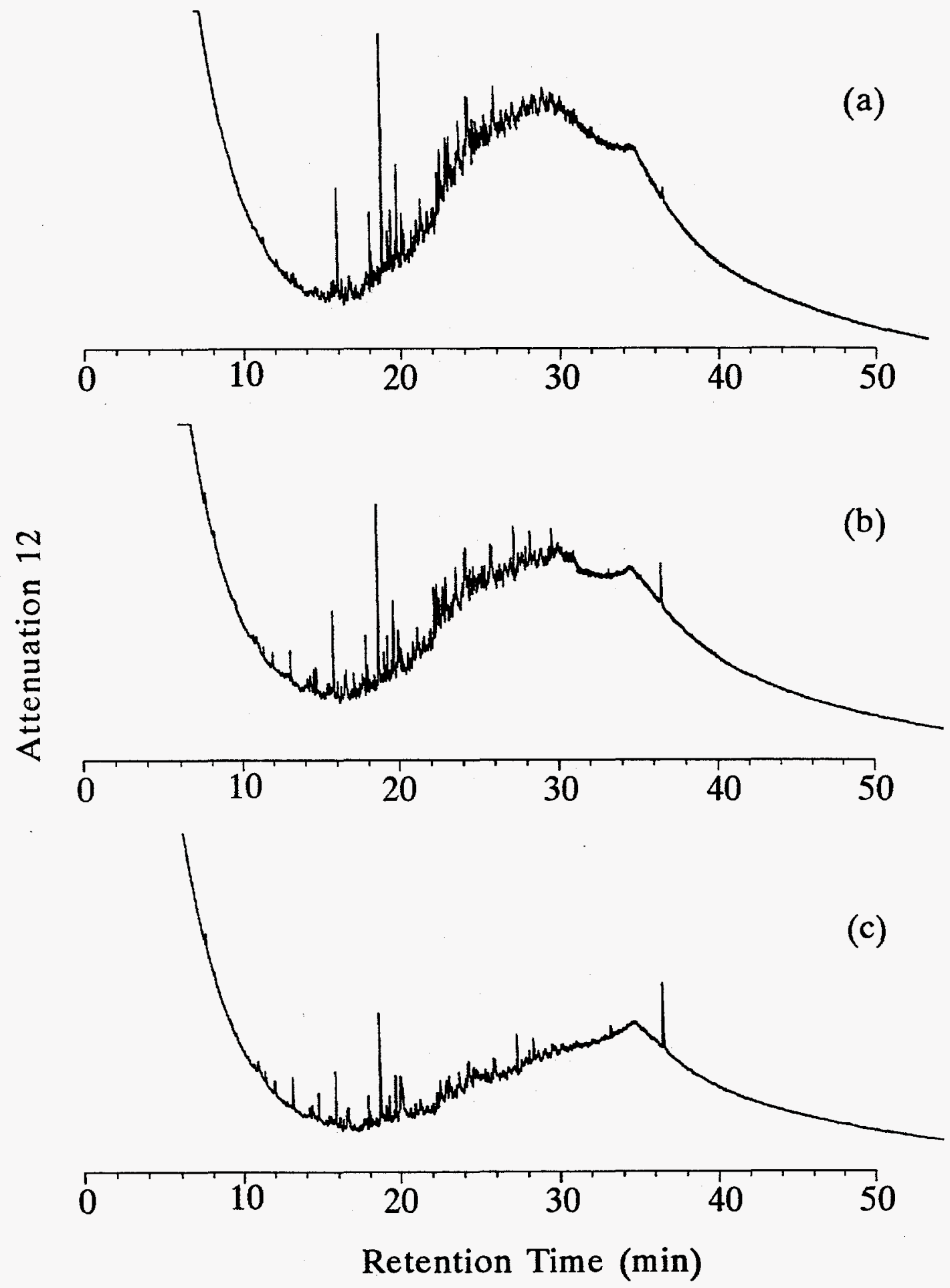

Figure 9. Nitrogen specific trace (NPD) chromatogram of: (a) untreated MWS, (b) treated with BNL-4-22, and (c) treated with BNL-4-23. 


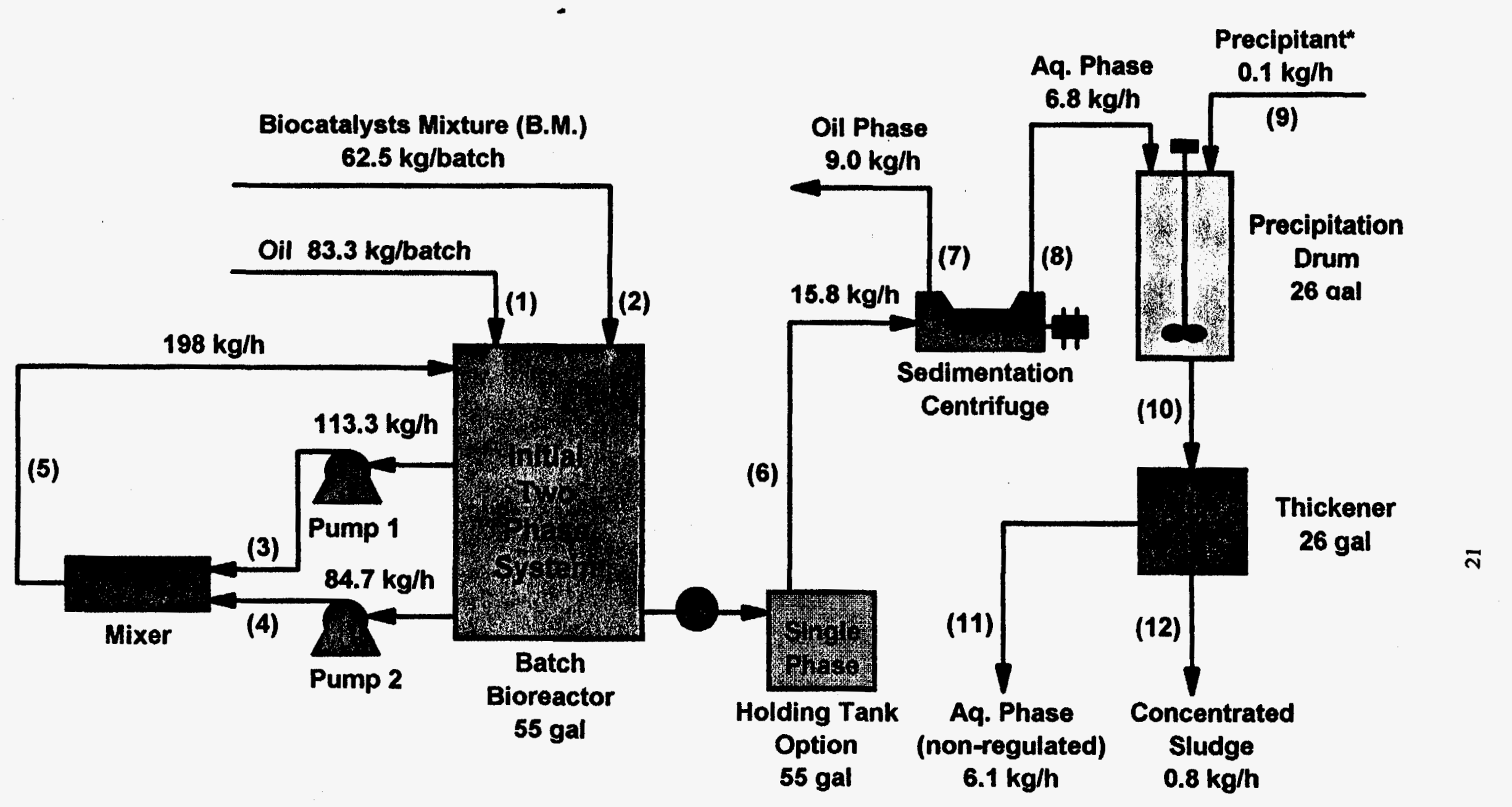

1. Biochemical batch process.

(36 hour pass)

2. Product and waste processing plant. (9.2 hour)

Figure 10. Biochemical process for upgrading of low grade oil (Batch per pass, 55 gal bioreactor, 1 set). 
总

爱

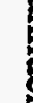

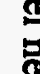

뭉

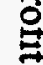

官

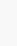

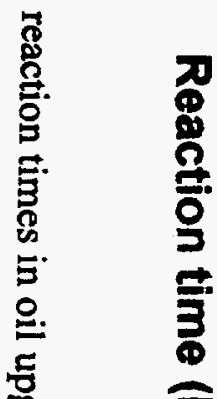

票

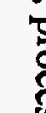

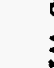

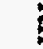

ํํำ

哭

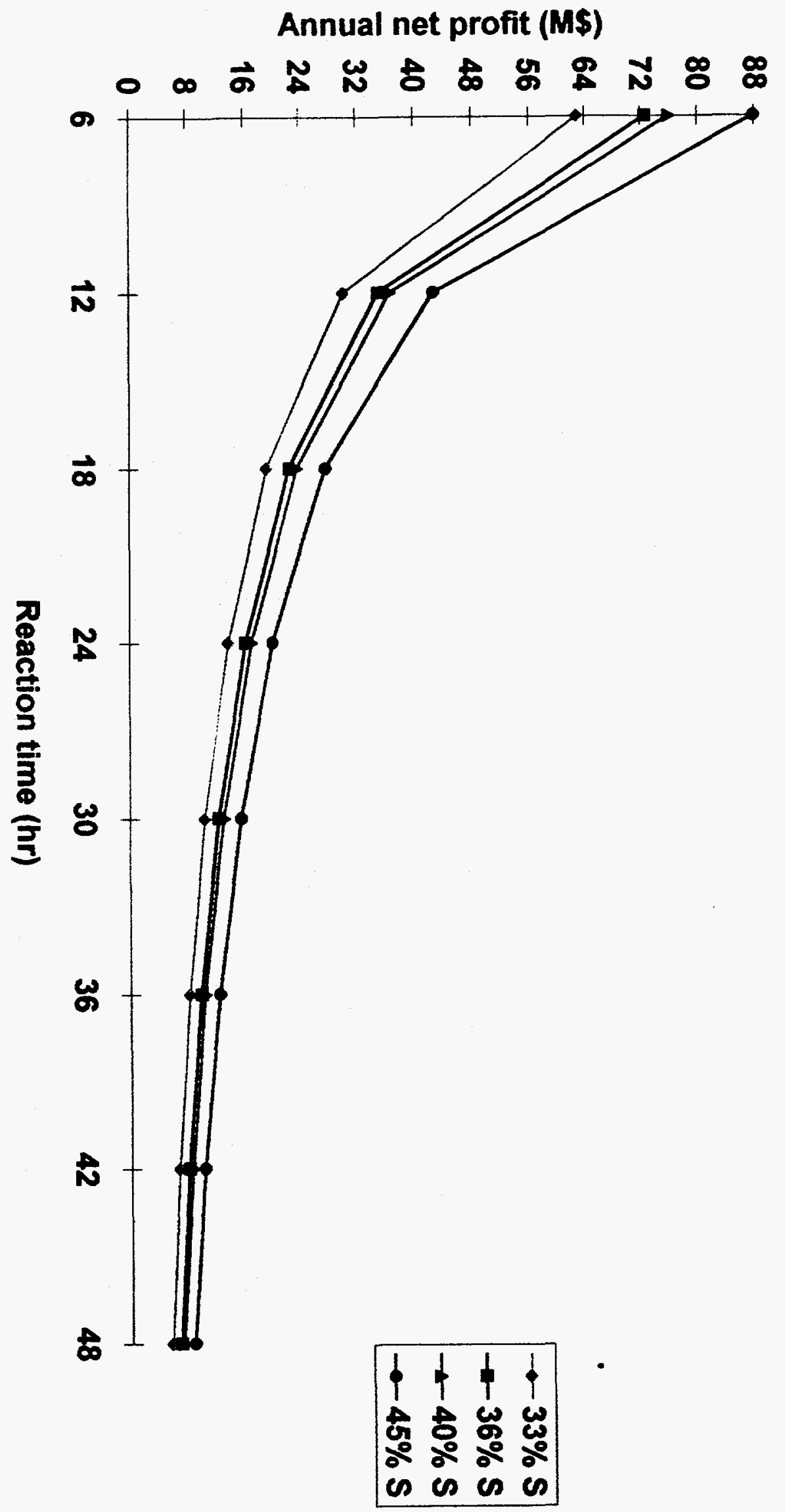




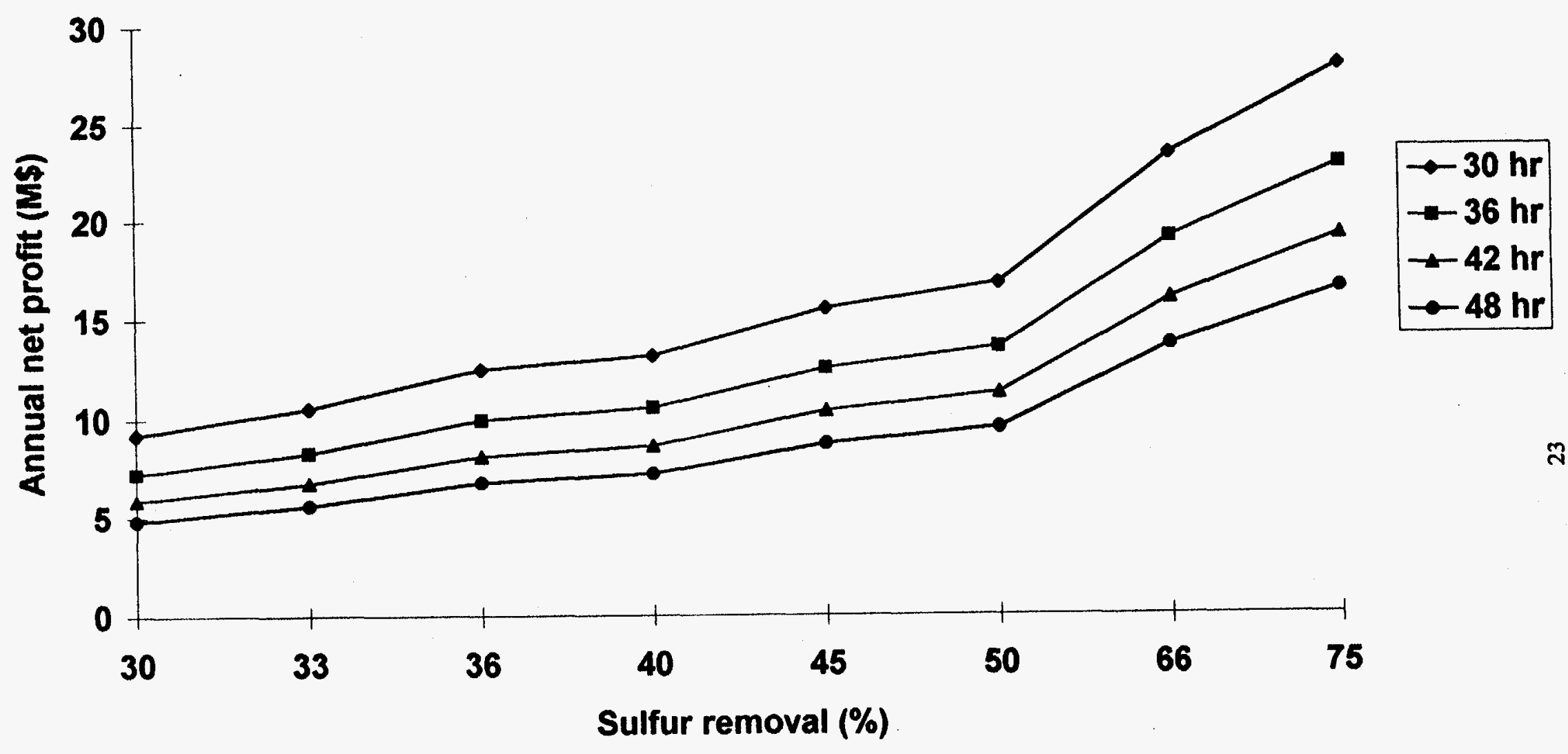

Figure 12. The annual net profit for various sulfur content removal in oil upgrading process at different reaction times $(1,000,000 \mathrm{gal}$ batch per pass). 


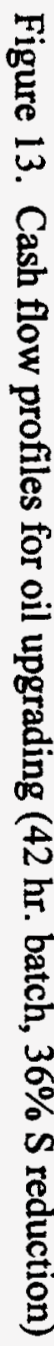

Cumulative discounted annual cash flows (\$M)
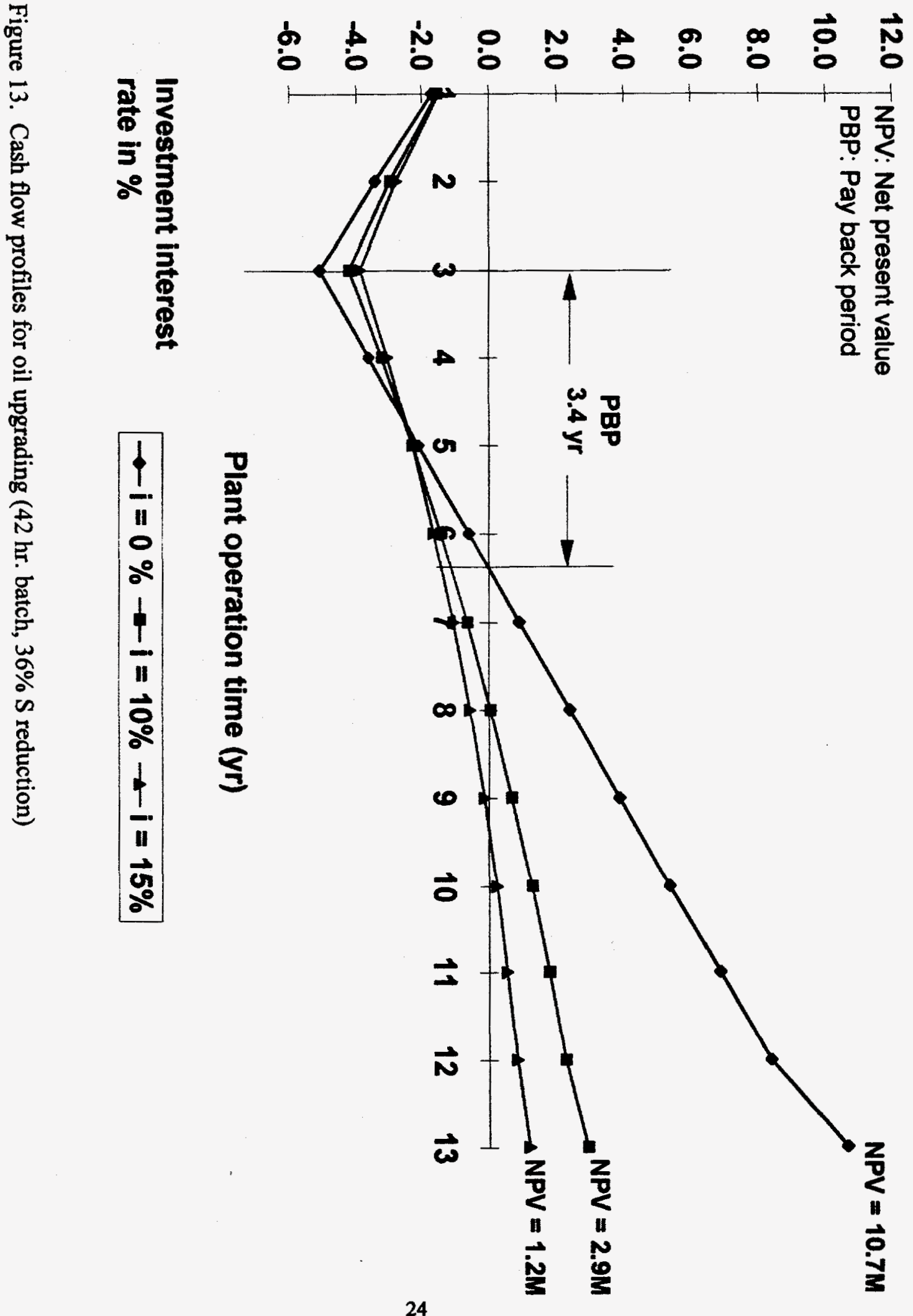
Cumulative discounted annual cash flows (\$M)

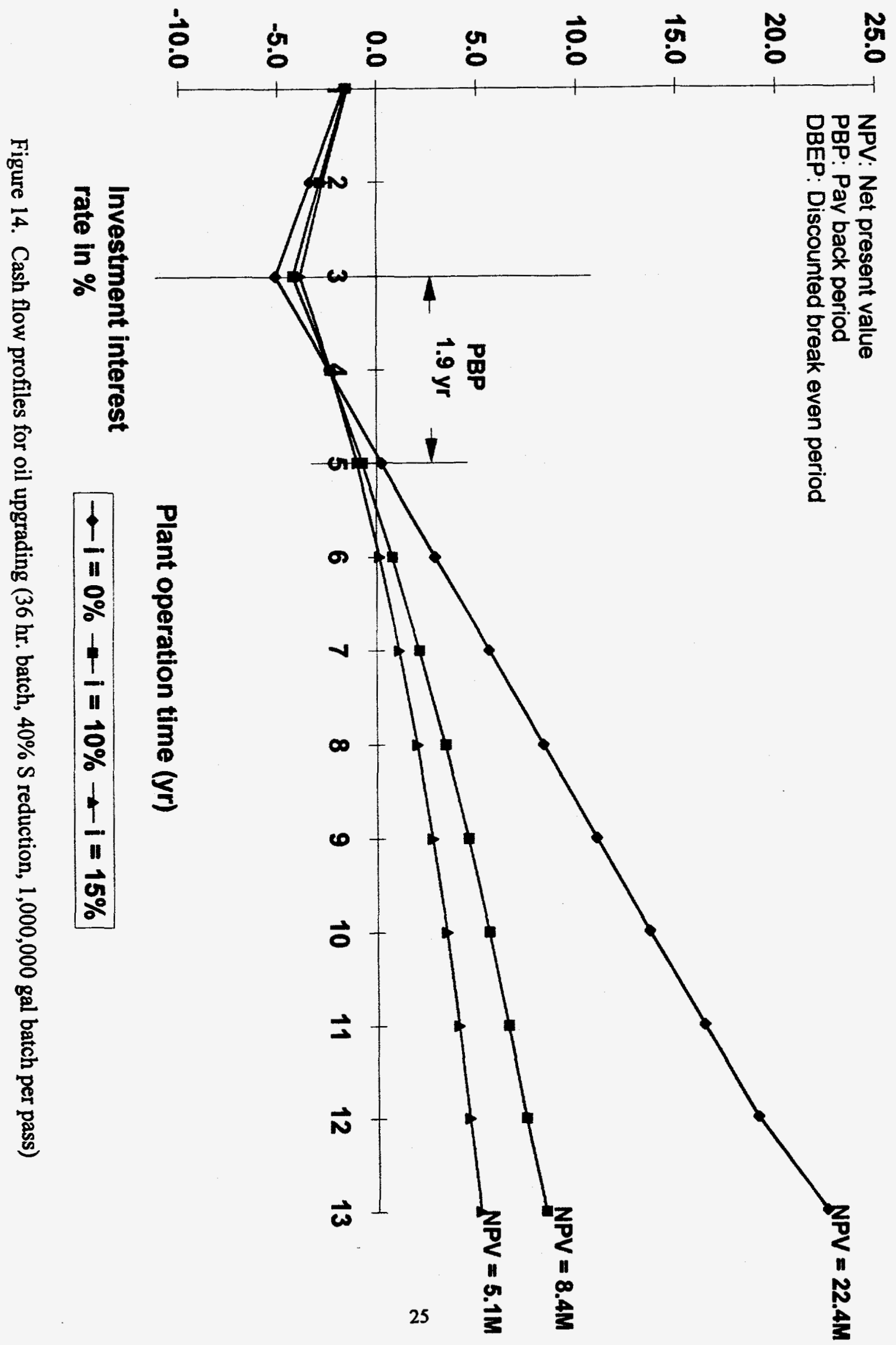

